practicing. as they leave one case and go to another, the same sort of personal eleanliness that surgeons practice in their work. Medical antisepsis is what is needed in the care of contagious diseases. Dr. Chapin wants all people to treat contagious disease exactly in that way, and he never can get them to do it so long as they believe that they can treat it as carelessly as they please, and when they get through call on the health officer to fumigate and thus stop off all sources of danger. He thinks that the psyehic effect of disinfection is wholly bad.

He said that instances (usually one) have been mentioned in which it seemed that a disease was transmitted by clothing or some other inanimate object. Dr. Chapin said that he did not deny that every single one of those cases referred to was caused in just exactly that way, but he would be entirely justified in doubting it, because no one presented any stronger evidence than the physicians who mentioned such cases in connection with yellow fever, and we now know that there was not the slightest basis of fact in any single one of those cases. The sole question we have to consider, he said, is whether or not that mode of dissemination of disease is an important factor in the maintenance of contagious disease in the community. $\mathrm{He}$ doc.3 not think that the advocates of disinfection have substantiated their theory that fomites are an important factor. This subject can only be settled in a statistical manner, and the collection of statistics is very difficult. There is no question but the chance of transmission in the ways suggested is greater in tuberculosis than in any other of the common diseases we have in this country. Dr. Chapin said that physicians often hear about cases of tuberculosis contracted in an infected house, but he has never seen that any infection in the lung diseases comes from the house, except in the living beings who are the occupants of the house. The men who advocate this theory of transmission by fomites should present evidence which is unimpeachable to support their view.

Dr. Chapin said that he believes in disinfection when there is reason. He thinks that we must treat different diseases in different ways. In his paper he said he referred chiefly to the routine work of the health officer in this country, and especially in the common diseases, such as scarlet fever, diphtheria, tuberculosis, typhoid, measles. He thinks that we should have disinfection in certain cases. In pandemics, suppose a person has been sick in a house for some time; no care has been taken; the patient is removed by death or otherwise; now if another and well family should come into that house he thinks that the house should be disinfected-not by the disinfection of sulphur and formaldehyd, but by elbow grease and soap and water. Even without this disinfection he thinks that the danger of infection of the second family is very slight. However, ninetenths of the disinfection done to-day after tuberculosis is, he maintains, where the patient has been sick with the disease and has remained in the family until removed by death, and the family is going to remain right in the same house; no precautions have been taken during the long course of the disease and they expect fumigation or disinfection by the health department is going to help them to atone for all past sins of omission. He gaid that it is wrong for him to do it and to confirm them in the wrong idea. Again, he is called on at times to disinfect for tuberculosis when the greatest precautions have been taken over a period of months or years. It seems to him that there is no use for it, that it is possible for a tuberculosis patient to live in a room with others and to work with them and not to infect them if he will only take care of his sputum. If that is true, there is no necessity for disinfecting a house which the patient has taken care to disinfect, or, rather, not to infect. Prictically, Dr. Chapin said, when the danger of infection is greatest there are very few cases in which disinfection is of the slightest good.

In diphtheria there is no question but that in a majority of cases it extends by means of bacilli in the throats and noses of well poople or of convalescent people, and it is perfectly absurd and wicked, he said, to disinfect a house where there has been diphtheria unless we are very sure that the people who live in the house are no Ionger infected. It is possible for us to learn whether or not the penple are infected. Isolation can not always be maintained in diphtheria until the physician is sure of non-infection; and, therefore, in Providence the plan of not disinfecting simply as routine was adopted. If any family wants disinfection they have to subject their throats and noses to two or more tests by culture and show that no bacilli are present. Dr. Chapin believes that the common contagious diseases are almost entirely carried by the direct contact of sick persons and infected well persons with the well; that is, by persons and not by things; and if that is so, disinfection of things, no matter how well carried out, can have no appreciable effect in checking the spread of these diseases. He believes that if to-day in the United States disinfecting after scarlet fever, diphtheria and tuberculosis should be stopped, it would not have the slightest effect on the prevalence of these diseases.

\section{STUDIES ON PHAGOCYTOSIS.*}

\author{
D. H. BERGEY, M.D.
}

Assistant Professor of Bacteriology. University of Fennsylvania. PHILADELPHIA.

The studies of Leishman, of Wright and Douglas, of Neufeld and Rimpau, of McFarland and Engle, and of others, have opened up a new field of investigation for the elucidation of the problem of the mechanism of immunity. 'The experiments that have been reported thus far have dealt almost entirely with the opsonic powers of the blood serum against staphylococci, streptococci and pneumococci, and the observations have been made exclusively on the phagocytic powers of the polymorphonuclear leucocytes, or the microphages of Metchnikoff.

It seemed desirable to ascertain whether the opsonic power of the serum was efficacious against other classes of micro-organisms, and also whether the macrophages of Metchnikoff participated in the phagocytosis. Metchnikoff himself states that in the resorption of animal cells in general it is especially the macrophages which intervene, but in natural immunity against micro-organisms positive chemiotaxis is exhibited by the microphages more than the macrophages. He states that the sensitiveness of the two chief categories of phagocytrs often exhibits a marked difference and that spirilla, for example, are ingested and destroyed exclusively by the macrophages of the guinea-pig which alone exhibit the necessary positive chemiotaxis. In many other examples of natural immunity the part played by the macrophages is masked by that of the microphages.

My own experiments were carried out with the peritoneal exudate of guinea-pigs following aleuronat injections. This exudate was mixed with equal quantities of .S5 per cent. sodium chlorid solution and then added to the various bacterial suspensions in equal proportions in capillary tubes. These tubes were incubated at from 34 to $36^{\circ} \mathrm{C}$. for thirty minutes when smears were prepared and the number of bacteria taken up by 20 microphages and by 10 macrophages estimated. For each test on such a peritoncal exudate fresh bacterial suspensions were prepared which contained as nearly as possible equal numbers of bacteria, but no attempt was made to have an equal number of bacteria for the several tests, so that the suspensions used for the different exudates did not contain equal numbers of bacteria.

A series of ten observations was carried out on the exudate obtained from ten different animals by employing the following cultures: Bacterium pseudodiph-

- Read in the Section on Pathology and Physiology of the American Medical Association, at the Fifty-seventh Annual Session, June. 1906 . 
theriticum; two cultures of Streptococcus pyogenes, one from urine and from the throat of a case of scarlet fever; Micrococcus catarhalis; Micrococcus pyogenes albus and Micrococcus aureus. The results obtained in these ten observations are shown in Tables 1 and 2 , Table 1 showing the average number of bacteria taken up by the microphages, Table 2 showing the average number of bacteria taken up by the macrophages. While there is considerable variation in the results obtained with the different exudates it will be seen that in a fairly constant degree the macrophages had taken up a greater number of bacteria than had the microphages. This fact is shown more definitely in the means of the ten observations in the last column of each table.

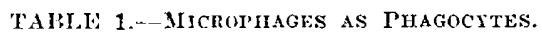

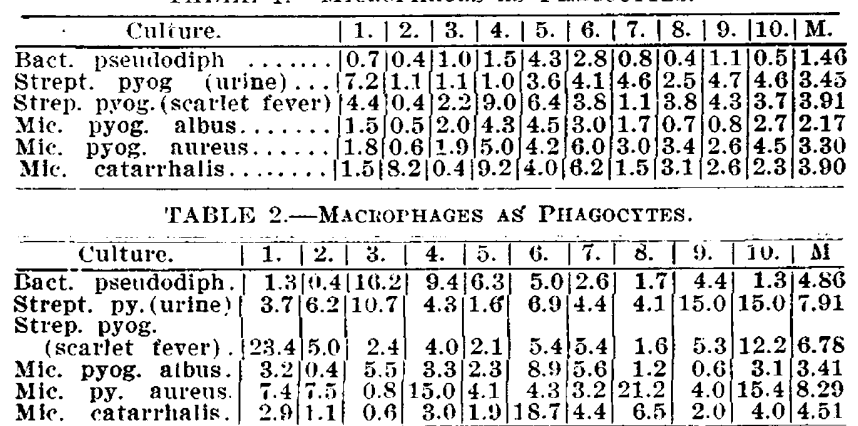

A second series of five experiments was undertaken with the view of ascertaining the range of bacteria susceptible to phagocytosis under similar conditions. For these observations the following organisms were $\mathrm{cm}-$ ploied: Micrococcus aureus; Microspira schuylkitliensis; and Bacillus dysenterice, Shiga. 'The results obtained in this series of observations are shown in Tables 3 and 4 . These results are too few in number and too erratic to warrant the formulation of any definite deductions. In several instances no phagocytic action could be demonstrated, and doubt existed usually whether the spirilla and dysentery bacilli were really within the phagocytes or were merely lying on them, or adherent to their exterior. 'The results indicate that the opsonic power of the blood serum is much more pronounced for those bacteria which induce septiccmia than for those in which a more distinct bactericidal immunity is induced.

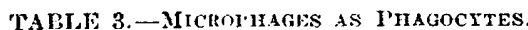

\begin{tabular}{|c|c|c|c|c|c|}
\hline Culture, & 1. & 2. & 3. & 4. & $\overline{5}$. \\
\hline $\begin{array}{l}\text { Mic. pyog. alleus } \\
\text { Me. sp. Schuylkill }\end{array}$ & 4.4 & $\begin{array}{l}2.0 \\
0.1\end{array}$ & $\begin{array}{l}0.8 \\
0.15\end{array}$ & $\begin{array}{l}2.0 \\
0\end{array}$ & $\begin{array}{l}2.5 \\
5.2\end{array}$ \\
\hline B. dysentertis ... & 0.6 & 0.6 & 0.7 & 0.6 & 3.0 \\
\hline
\end{tabular}

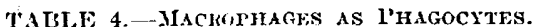

\begin{tabular}{|c|c|c|c|c|c|}
\hline Cultiu'e. & 1. & 2. & 3. & 4. & $\overline{\mathbf{5}}$. \\
\hline $\begin{array}{l}\text { Mile pyog anrells. } \\
\text { Mc. sp. Schuylkill }\end{array}$ & $\begin{array}{l}7.2 \\
8.6 \\
3.0\end{array}$ & $\begin{array}{l}2.0 \\
0.6 \\
0\end{array}$ & $\begin{array}{l}1.6 \\
0 \\
2.3\end{array}$ & $\begin{array}{l}2.5 \\
2.6 \\
0\end{array}$ & $\begin{array}{l}0.5 \\
6.2 \\
3.0\end{array}$ \\
\hline
\end{tabular}

Paralysis of Ocular Muscles After Lumbar Anesthesia.Loeser of Berlin publishes in $M \epsilon d$. Klinik for March 11 reports of 3 cases of paralysis of the ocular muscles observed after spinal analgesia. The first patient was a man of 45 , operated on for hydrocelc. The evening after the operation, while healing was progressing smoothly, intense headache developed and vomiting. The headache continued, and when the patient got up for the first time on the fifth day, he presented symptoms of trochlear paralysis on the right side. Recovery was complete in a week or so. The second and third patients had been operated on for hemorrhoids or hernia under stovain; spinal analgesia, and abducent paralysis developed in direct connection with the operation. This paralysis subsided very slowly. In all the cases the first symptoms were noticed as the patient first left his bed.

\section{Clinfcal Notes}

\section{THE TREATMENT OF FRACTLRES OF THE FEMUR}

WITH A DOUBLE ANGLIAR PLASTER-OF-PARIS SPLANT AND ITS APPIICATION BY A SECTIONAL METIIOD.

\author{
J. H. DOWNEY, M.D. \\ GAIXESTILL; GA.
}

Owing to the difficulty of obtaining the results without deformity and the great suffering and long confinement of patients suffering from fractures of the femur, this condition has interested the profession from time inmemorial.

The different methods, devices and apparatus devised for the treatment of these fractures are too numerous to mention, and I have not added another wholly new one to this list, but have tried to get the best points of each and to combine them into one which will meet every indication of any fracture of the femur, whether of the neck, upper, middle or lower third, and one open to the fewest rational objections. It is conceded that no straight splint can be employed successfully in fractures of the upper and lower end of the femur. If this be true, then the straight plaster cast, Buck's extension and the long-side splint of Hamilton must be laid aside or used only in fractures of the middle third. 'The recognition of this fact led Esmarch to use a double incliner plane, Nathan R. Smith to devise his long anterior splint and, later, Holgen his posterior suspension. These three last methods had the important idea in view of making the long fragment conform in direction to the short one, and at the same time to get the nearest approach to a natural restful position of the $l e g$ and greatest amount of normal muscular relaxation. Wach of these methods meets the indications mentioned, provided the patient can be kept still, yet none of them meets the fundamental indication for which they wore devised. "The objects in the treatment are to roluce the fracture, to maintain reduction immobilized until union is firm, and to restore the leg to its normal usefulness."

Does any methor given in our text-bnoks to-rlay meet the above-mentioned objects in treatment? I believe nearly all will agree with me that they do not. and most of them seem to have things reversed, as, e. g.. the immobilization of the patient instear of the fracture. Each splint or device I have spoken of has many merits, especially the Modgen, and I lo not speak of them in a spirit of criticism, by any means. They have each served the profession well and have aided in relieving suffering humanity. As we can never reach a state of perfection, we must always be looking for something better. Let us combine the good points of all these methods and see if we can not meet all these requirements and at the same time give the patient a reasonable degree of com. fort and safety and the freedom of any desired movement during this long process of repair without increase in present pain or risk of future deformity. Esmarch. Smith. Hodgen and Cabot's apparatus give us position; Buck's apparatus, extension; plaster-of-Paris, fixation.

$$
\text { AUTIOR'S DEVICE. }
$$

I want to combine all these important points in one unirersal dressing linown as the double angular plasterof-Paris splint, which. if properly applicd. will meet crerr indication.

'To illustrate, let us assume that we have a supercondrloid fracture. We must flex tire leg on the thich 